\title{
A Quantitative Measure For Evaluating Project Uncertainty Under Variation And Risk Effects
}

\author{
Ali Chenarani \\ National Aerospace University «KhAI» \\ Kharkiv, Ukraine \\ Alichen.ua@gmail.com
}

\author{
E. A. Druzhinin \\ National Aerospace University «KhAI» \\ Kharkiv, Ukraine \\ K105@d1.khai.edu
}

\begin{abstract}
The effects of uncertainty on a project and the risk event as the consequence of uncertainty are analyzed. The uncertainty index is proposed as a quantitative measure for evaluating the uncertainty of a project. This is done by employing entropy as the indicator of system disorder and lack of information. By employing this index, the uncertainty of each activity and its increase due to risk effects as well as project uncertainty changes as a function of time can be assessed. The results are implemented and analyzed for a small turbojet engine development project as the case study. The results of this study can be useful for project managers and other stakeholders for selecting the most effective risk management and uncertainty controlling method.
\end{abstract}

Keywords-project uncertainty index; entropy; risk management; rework risk; research and development project

\section{INTRODUCTION}

One of the most prominent aspects of each project and especially complex projects is the influence of uncertainty on achieving the project goals. In a project, the uncertainty is maximum at the beginning and as the information and knowledge about the project is attained and as activities terminate, uncertainty decreases and reaches its minimum value at the project's end [1]. A well-known aspect of uncertainty is imprecision or variation of project parameters such as duration, cost, work amount (effort). Another aspect is foreseen uncertainty, which causes risks [2]. Risk is defined as an uncertain event or condition that, if occurs, has a positive or a negative effect on at least one project objective, such as time, cost, scope, or quality [1]. Therefore, due to the significant impact of uncertainty on project goals, quantification and monitoring this concept can be very useful and informative for project manager and other stakeholders. However, in this area and its practical use in project management, little progress has been achieved so far [3]. Considerable part of limited researches on this field employed the entropy concept [3-8]. However, these researches do not investigate the contribution of each activity on project uncertainty depending on its position in the project's schedule. In addition, the effect of complex combination of risks, which affects the distributions of activity durations and costs have not been analyzed in detail. One of the first works on quantification of uncertainty in a project was performed in [4] where the authors proposed the entropy as a measure of project uncertainty and implemented entropy concept for a project with deterministic PERT distribution and uncertain durations. They suggested decreasing project entropy level at project milestones and implemented the results in a petroleum plant project in Russia. In [8], entropy was employed and a detailed description of uncertainty for organizational and economic systems was proposed. A method for estimating uncertainty was proposed that consisted of four parts: the uncertainty of the environment; uncertainty of managerial decision-making; uncertainty of consequences and future implementation of management decisions and vartational uncertainty.

In $[9,10]$, authors proposed the use of entropy for evaluating the risks and uncertainties of a project. In [3], authors offered three entropy-based uncertainty measures for evaluating the project uncertainty: aggregate uncertainty, weighted aggregate uncertainty and deviation uncertainty. The proposed method is based on the number of unknown risk factors and their weight at each project stage, which is evaluated by experts. The employment of entropy as the third risk characteristic (besides probability and impact of risk) for assessing risks of software development projects is suggested in [5]. Authors introduced entropy as a measure of uncertainty about the probability of risk occurrence. They assessed the entropy of risks by a questionnaire survey and implemented a risk fuzzy judgment method for a group of software projects. In [11], authors used fuzzy entropy and the VIKOR technique for evaluation and prioritizing risks of Engineering, Procurement and Construction (EPC) projects. In their work, fuzzy entropy is used for calculating the weights of criteria. In [6], authors employed a weighted linear average of Expected Utility and Entropy (EU-E) decision model for measuring uncertainty of different possible variants for realization of resource constrained project with uncertain activity durations. In [12], authors proposed a Markov chain model for assessing the risks of life safety projects, which allows moving from onedimensional to multi-dimensional assessments of the level of security in organizational and technical systems. Finally, in [7], entropy was applied as a measure of uncertainty for two project parameters, i.e. project completion time and critical path probability. The required distributions are obtained by ARENA simulation software for a project network with PERT distributions. 
A measure for project uncertainty that takes into account the mentioned factors is proposed in this work. The results are implemented in practice for a small turbojet engine development project.

\section{PROPOSED APPROACH}

\section{A. Basics, Entropy as a measure of uncertainty}

Entropy concept is used widely as a measure of uncertainty in different fields. For the first time, Boltzmann in 1872 in his work on theory of gases introduced entropy. His famous equation relates the entropy of an ideal gas to the number of real microstates consistent with its macrostate properties. This way, the entropy value represents the number of possible statuses of a system, and consequently the degree of disorder and disorganization of a system. In [13], the concept of entropy for measuring information uncertainty was developed. The information was defined as removed uncertainty and the use of entropy as a measure of information related to the message was suggested. In other words, the uncertainty of a system decreases by receiving information about the possible outcomes of the system. Entropy formula has the following form:

$$
\mathrm{H}=-\sum_{\mathrm{i}=1}^{\mathrm{N}} \mathrm{p}_{\mathrm{i}} \ln \mathrm{p}_{\mathrm{i}}
$$

Where:

$\mathrm{H}$ : entropy of system, $\mathrm{N}$ : the number of possible outcomes or states of a given system, $\mathrm{p}_{\mathrm{i}}$ : probabilities of those outcomes or states and we have $\sum \mathrm{p}_{\mathrm{i}}=1$.

In [4], the entropy concept in project management field was developed and calculating entropy of each activity regarding to duration, cost and other project parameters and adding the entropy of activities for obtaining the total entropy of project was suggested. In other words:

$$
\mathrm{H}=\sum_{\mathrm{ID}} \mathrm{h}_{\mathrm{ID}}
$$

Where: $h_{I D}$ is the entropy of an individual activity and

$$
\mathrm{H}_{\text {project }}=\mathrm{H}_{\text {schedule }}+\mathrm{H}_{\text {cos } \mathrm{t}}+\mathrm{H}_{\text {quality }}+\ldots
$$

In next section, we will further develop this concept along with introducing other aspects, which contribute to the uncertainty of the project. Hence, we suggest an uncertainty index for project by employing these factors.

\section{B. Developing the project uncertainty index}

In this research, a project simulation program which is presented in [14] has been employed. This program uses a discrete event based Monte Carlo method and models the project with and without considering risk factors when activities have uncertain cost and duration values. Durations and cost of activities can be determined by probability distributions such as triangular, normal or beta-distribution. As noted before, this aspect of uncertainty is called variation [2].
On the other hand, risks are consequences of uncertainty, which are specified by two parameters, probability of occurrence (P) and impact of risk (I). For simulating risks in project, depending on their effect on main project constraints we categorized them into four types (delay risks, cost risks, excess work risks and rework risks). As the result of simulation, the duration and cost of each activity as well as cumulative time and cost of project are obtained in form of histogram distributions or CDFs (cumulative distribution function). Figure 1 shows a summary of simulation program inputs and outputs.
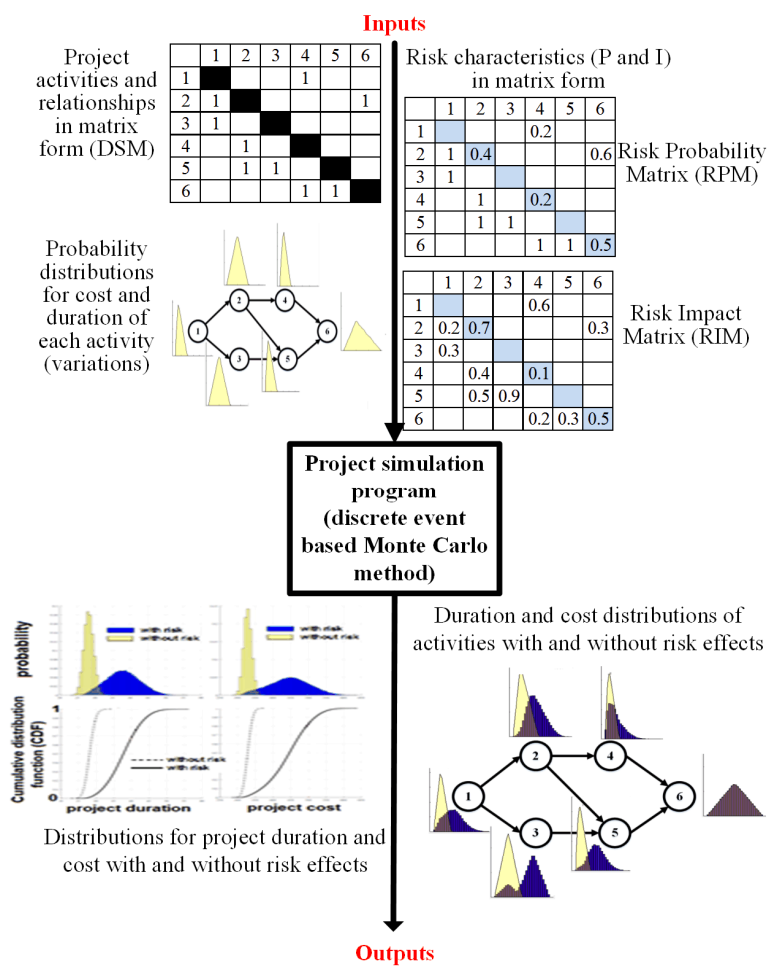

Fig. 1. Summary of simulation program inputs and outputs

In order to formulate the uncertainty index, for example we consider the uncertainty of activities with respect to their durations. We define $\mathrm{U}_{\mathrm{t}}$ as duration uncertainty index of activity $i$ as:

$$
\mathrm{U}_{\mathrm{ti}_{\mathrm{i}}}=\mathrm{H}_{\mathrm{t}_{\mathrm{i}}} \overline{\mathrm{t}}_{\mathrm{i}}\left(1+\mathrm{I}_{\mathrm{ti}}\right)
$$

Where $\mathrm{H}_{\mathrm{t}_{\mathrm{i}}}$ =non-dimensional entropy of activity $i$ with respect to its duration distribution, $\overline{\mathrm{t}}_{\mathrm{i}}=$ average (mean) value for duration of activity $i, \mathrm{I}_{\mathrm{t}}=$ uncertainty propagation factor of activity $i$ with respect to duration

Each part of (4) is obtained as follows:

$\mathrm{H}_{\mathrm{t}_{\mathrm{i}}}$ for each activity is calculated by using the distribution of that activity's duration, which is achieved by simulation results. Figure 2 shows an example of obtained distribution for duration of an activity for two cases i.e. simulation with and 
without considering risk factors. In this case, the initial distribution for duration of activity was triangular distribution (white histograms), after simulating the effect of project risks, the yellow histogram is obtained for duration of activity. We calculate the non-dimensional entropy of this activity's duration as:

$$
\begin{aligned}
& \mathrm{H}_{\mathrm{t}_{\mathrm{i}}}=\frac{\mathrm{h}_{\mathrm{t}_{\mathrm{i}}}}{\mathrm{h}_{\mathrm{t}_{\max }}}=\frac{1}{\ln \mathrm{n}_{\mathrm{t}}} \sum_{\mathrm{j}=1}^{\mathrm{n}_{\mathrm{t}}} \mathrm{p}_{\mathrm{j}} \ln \mathrm{p}_{\mathrm{j}} \\
& \text { Where } \mathrm{n}_{\mathrm{t}}=\frac{\Delta \mathrm{T}}{\Delta \mathrm{t}}=\frac{\left(\mathrm{t}_{\max }-\mathrm{t}_{\min }\right)}{\Delta \mathrm{t}} \\
& \text { and } \mathrm{p}_{\mathrm{j}} \ln \left(\mathrm{p}_{\mathrm{j}}\right)=0 \text { when } \mathrm{p}_{\mathrm{j}}=0
\end{aligned}
$$

The coefficient $\ln n_{t}$ is maximum possible entropy value and happens for uniform distribution. Equation (5) is used for calculating the entropy of both distributions, i.e. with and without considering risk effects.

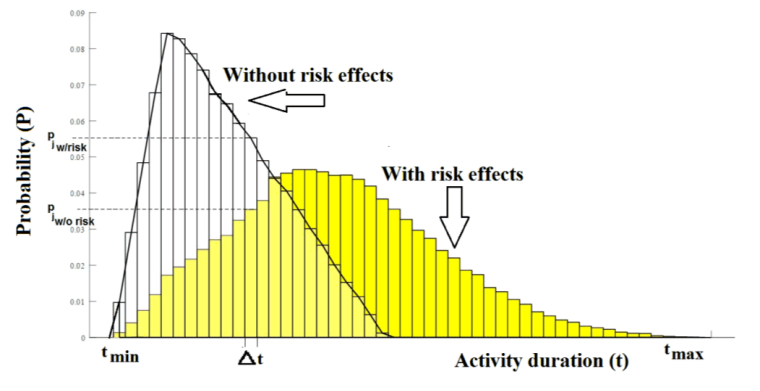

Fig. 2. Histograms for duration of an activity

Selecting the appropriate value of $\Delta \mathrm{t}$ is important for achieving the suitable results [4]. For determining this parameter, we must take into account two considerations. The first consideration is that the size of $\Delta \mathrm{t}$ compared with sampling interval $\left(\mathrm{t}_{\max }-\mathrm{t}_{\min }\right)$ must be small enough in order to properly reflect the form of distribution. Another consideration is that $\Delta \mathrm{t}$ value cannot be so small as it causes the low density of samples in intervals. These considerations can be expressed by next inequality:

$$
\frac{\Delta \mathrm{T}}{\mathrm{N}}<<\Delta \mathrm{t}<<\Delta \mathrm{T}
$$

Where $\mathrm{N}$ is the total number of samples (in our simulation program it is equal to iteration number $)$ and $\Delta \mathrm{T}=\left(\mathrm{t}_{\max }-\mathrm{t}_{\min }\right)$. The suitable value of $\Delta \mathrm{t}$ can be obtained by a simple try and error process. In cases where the order of durations for different activities differ significantly, this process can be more complex. The value of $\Delta \mathrm{t}$ must be equal in both cases of Figure 2 in order to compare their entropies.

The next coefficient in (4) is $I_{t_{i}}$ or uncertainty propagation factor which shows the potential ability of an activity in propagating the uncertainty through the project. For first activities, this parameter is higher than last activities. For example for the network diagram of a project which is shown in Figure 3, the uncertainty about the third activity affects 8 successor activities but for activity 12 only 2 activities are affected. For computing this coefficient, we use graph theory for searching and finding the affected activities for each activity.

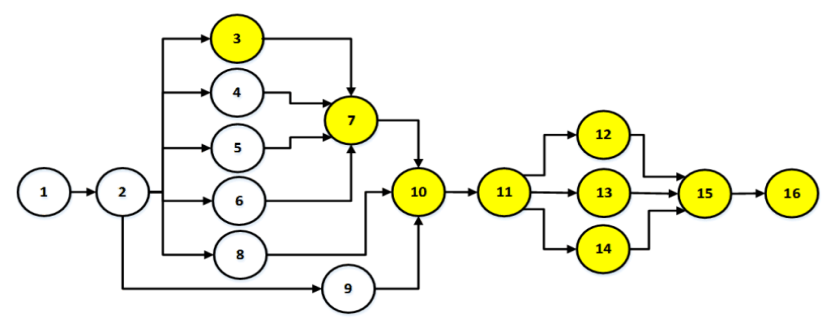

Fig. 3. Example of a project's network diagram

If the directional graph of project is represented by:

$\mathrm{G}=(\mathrm{V}, \mathrm{A})$

We have:

$\mathrm{V}=\{1,2, \ldots, \mathrm{n}\}$, set of vertices (project activities)

$\mathrm{n}=|\mathrm{V}|$ is graph order (number of project activities) and

$$
\mathrm{A}=\{(\mathrm{u}, \mathrm{v}) \mid 1 \leq \mathrm{u}<\mathrm{n}, 1<\mathrm{v} \leq \mathrm{n}, \mathrm{u} \neq \mathrm{v}\}
$$

set of edges (activity dependencies)

For calculation of $I_{t_{i}}$ in (4) for each activity, we create a directional subgraph, which corresponds to vertex $i$. This is performed via a graph traversal algorithm. In present study, we used BFS (breadth first search) method and as the result, all vertices (project activities) and edges (activity dependencies) which start from $i$ th vertex (activity) are found. Therefore, the obtained subgraph $G_{i}=\left(V_{i}, A_{i}\right)$ is directional subgraph that starts from $i$ th vertex and we have:

$$
\mathrm{V}_{\mathrm{i}} \subseteq \mathrm{V}, \mathrm{V}_{\mathrm{i}}=\{\mathrm{j}\}, \mathrm{j} \in\{\mathrm{i}, \ldots, \mathrm{n}\}
$$

$\mathrm{V}_{\mathrm{i}}$ is the set of activities affected by activity $i$ and it's order (number of project activities dependent on that activity) is represented by $n_{i}=\left|V_{i}\right|$. In addition, we have:

$$
\mathrm{A}_{\mathrm{i}} \subseteq \mathrm{A}, \mathrm{A}_{\mathrm{i}}=\left\{\left(\mathrm{u}_{\mathrm{i}}, \mathrm{v}_{\mathrm{i}}\right)\right\}, \mathrm{u}_{\mathrm{i}} \in\{\mathrm{i}, \ldots, \mathrm{n}-1\}, \mathrm{v}_{\mathrm{i}} \in\{\mathrm{i}+1, \ldots, \mathrm{n}\}
$$

After obtaining $G_{i}$, the $I_{t_{i}}$ value is calculated as follows:

$$
\begin{aligned}
& i_{t_{i}}=\sum_{j=1}^{n_{i}}\left[\bar{t}_{u_{i}(j)} I\left(u_{i}(j), v_{i}(j)\right)\right] \\
& I_{t_{i}}=\frac{i_{t_{i}}}{i_{t_{\max }}}=\frac{i_{t_{i}}}{i_{t_{1}}}
\end{aligned}
$$

(The maximum value of this coefficient belongs to first activity because all project activities are affected by it). 
$I\left(u_{i}, v_{i}\right)$ in (13) is an estimate of predecessor activity $\left(u_{i}\right)$ impact on successor activity $\left(v_{i}\right)$ in form of the ratio of received and used data, documentation, raw material etc. and can be determined by different methods. In this work, we employed the expert method. Finally, the last part of (4) is the mean value for duration of $i$ th activity $\left(\overline{\mathrm{t}}_{\mathrm{i}}\right)$ which is obtained by the simulation program. This part is employed for the evaluation of each activity's contribution in project uncertainty with respect to the assumed parameter (project duration is this case). After calculating uncertainty index for all activities with (4), the duration uncertainty index of project as a function of time, is obtained as:

$$
\mathrm{U}_{\mathrm{t}_{\text {project }}}(\mathrm{t})=\frac{1}{\mathrm{U}_{\left.\mathrm{t}_{\text {project }}\right|_{\mathrm{t}=0}}} \sum_{\mathrm{i}} \mathrm{k}_{\mathrm{i}} \mathrm{U}_{\mathrm{t}_{\mathrm{i}}}
$$

Where $\mathrm{i} \in\left\{1,2, \ldots, \mathrm{N} \mid \mathrm{w}_{\mathrm{i}} \neq 0\right\}, \mathrm{N}=$ the total activity number of project, $\mathrm{U}_{\left.\mathrm{t}_{\text {project }}\right|_{\mathrm{t}=0}}=$ maximum value of duration uncertainty index of project, which occurs at the beginning of project $(\mathrm{t}=0)$. Coefficient $\mathrm{k}_{\mathrm{i}}$ is the remained work fraction of $i$ th activity $\left(\mathrm{w}_{\mathrm{i}}\right)$ at time $\mathrm{t}$. In other words, the summation is performed over unfinished parts of activities. The unfinished activity set and their $\mathrm{k}_{\mathrm{i}}$ coefficients are obtained by project simulation program at every time step. The calculated uncertainty index is maximum at the beginning of project and as an activity accomplishes, the corresponding uncertainty index value is subtracted. When project finishes, the uncertainty index equals zero. Similarly, uncertainty index for cost of activities and project can be obtained as follows:

$$
\mathrm{U}_{\mathrm{c}_{\mathrm{i}}}=\mathrm{H}_{\mathrm{c}_{\mathrm{i}}} \overline{\mathrm{c}}_{\mathrm{i}}\left(1+\mathrm{I}_{\mathrm{c}_{\mathrm{i}}}\right)
$$

Where $\mathrm{U}_{\mathrm{c}_{\mathrm{i}}}$ is the cost uncertainty index for activity $i$

$$
\begin{aligned}
& \mathrm{H}_{\mathrm{c}_{\mathrm{i}}}=\frac{\mathrm{h}_{\mathrm{c}_{\mathrm{i}}}}{\mathrm{h}_{\mathrm{c}_{\max }}}=\frac{1}{\ln \mathrm{n}_{\mathrm{c}}} \sum_{\mathrm{j}=1}^{\mathrm{n}_{\mathrm{c}}} \mathrm{p}_{\mathrm{j}} \ln \mathrm{p}_{\mathrm{j}} \\
& \mathrm{U}_{\mathrm{c}_{\text {project }}}(\mathrm{t})=\frac{1}{\mathrm{U}_{\left.\mathrm{c}_{\text {project }}\right|_{\mathrm{t}=0}}} \sum_{\mathrm{i}} \mathrm{k}_{\mathrm{i}} \mathrm{U}_{\mathrm{c}_{\mathrm{i}}}
\end{aligned}
$$

Where: $U_{c_{\text {project }}}(t)$ is the cost uncertainty index of project.

Then, we represent the overall index of project uncertainty as follows:

$$
\begin{aligned}
& \mathrm{U}_{\text {project }}=\left(\frac{1}{\mathrm{~K}+1}\right)\left(\mathrm{U}_{\mathrm{t}_{\text {project }}}(\mathrm{t})+\mathrm{KU}_{\mathrm{c}_{\text {project }}}(\mathrm{t})\right) \\
& 0 \leq \mathrm{U}_{\text {project }} \leq 1 .
\end{aligned}
$$

Coefficient $\mathrm{K}$ shows the importance of project cost uncertainty in relation with duration uncertainty. Depending on project type, the manager can determine whether the cost uncertainty or duration uncertainty is more important and assign the degree of that importance relationship.
In order to have a good representation of risk effects on a project, these calculations are performed for two cases: without considering risk effects and with risk effects (these two cases are illustrated in Figure 2). If there is another important aspect or parameter of project uncertainty (for example quality, work volume, technical characteristics etc) the overall concept can be applied provided that the distribution of that parameter for each activity can be evaluated or measured.

\section{CASE STUDY RESUlTS}

The results of this study were implemented for a small turbojet engine development project as the case study. This engine type can be installed on unmanned aerial vehicles or ultralight sport planes. The project consists of 5 phases and 63 activities. The overall project duration and cost without existing risk factors and with determined (certain) duration of activities are 4 years and 1 million dollars respectively. The Gantt chart diagram for this project is shown in Figure 4. For representing the uncertainty about activity durations and cost, triangular distribution is considered for each activity. Each triangle distribution is characterized by three parameters: optimistic estimate, most likely estimate and pessimistic estimate. In addition, for this project, a total number of 41 possible risks are identified by experts and are listed in detail in Table I.

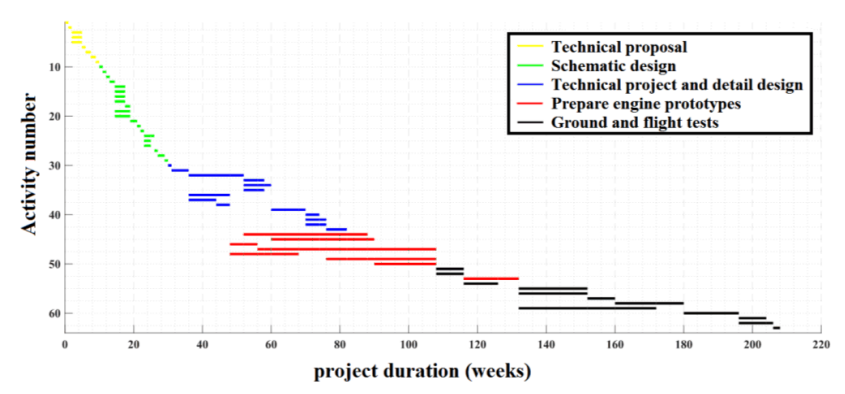

Fig. 4. Project Gantt chart

TABLE I. NUMBER OF INDENTIFIED RISKS FOR CASE STUDY PROJECT

\begin{tabular}{|c|c|c|c|c|}
\hline \multirow{2}{*}{ Project phase } & \multicolumn{4}{|c|}{ Number of risks } \\
\cline { 2 - 5 } & $\begin{array}{c}\text { Delay } \\
\text { risk }\end{array}$ & $\begin{array}{c}\text { Cost } \\
\text { risk }\end{array}$ & $\begin{array}{c}\text { Excess } \\
\text { work } \\
\text { risk }\end{array}$ & $\begin{array}{c}\text { Rework } \\
\text { risk }\end{array}$ \\
\hline Technical proposal & 1 & 0 & 1 & 3 \\
\hline Schematic design & 2 & 1 & 1 & 7 \\
\hline Technical project and detail design & 1 & 0 & 1 & 1 \\
\hline Preparing engine prototypes & 4 & 3 & 2 & 0 \\
\hline Ground and flight tests & 2 & 1 & 2 & 9 \\
\hline Total & 10 & 5 & 7 & 19 \\
\hline
\end{tabular}

The estimated probabilities and impacts of risks are entered in corresponding probability and impact matrices (simulation inputs, Figure 1). We obtained distributions of duration and cost of each activity with and without risk effects by employing the simulation program. The entropy of each activity is calculated by averaging the values of $\mathrm{H}_{\mathrm{t}_{\mathrm{i}}}$ in (5) and $\mathrm{H}_{\mathrm{c}_{\mathrm{i}}}$ in 
(17). The entropy increase for each activity due to risk effects is shown in Figure 5.

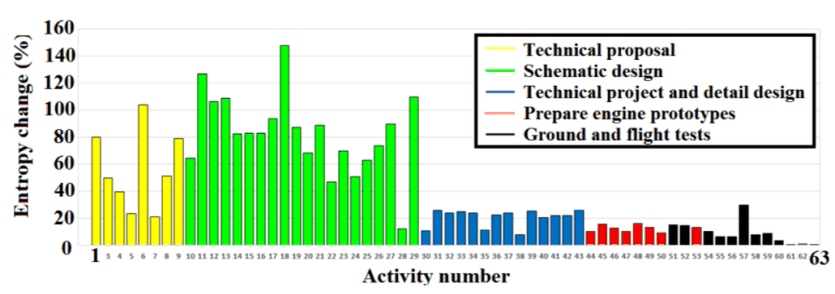

Fig. 5. Entropy increase of activities because of risk effects

Figure 5 shows the uncertainty increase for each activity when simulation program models all possible risks. In order to investigate the effects of each phase's risks on overall project uncertainty index, Figure 6 is represented. For this end, the simulation program was executed five more times. Each time, risks of one phase were ignored and the project uncertainty index at the project start was calculated for duration and cost uncertainty (i.e. $\mathrm{U}$ in (15) and $\mathrm{U}$ in (18)). The ratios of uncertainty increase due to ignoring risks of each phase to its maximum value (which obtains after modeling all possible risks) are calculated and shown in figure 6 .

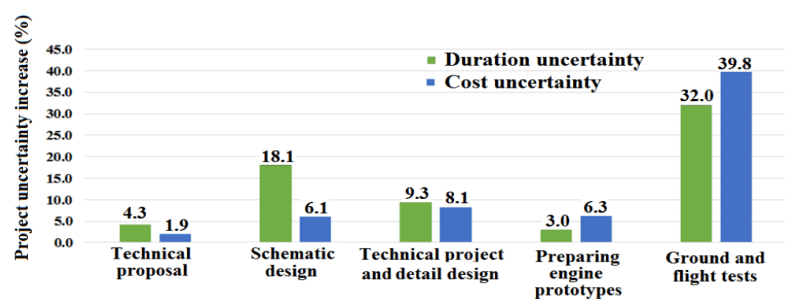

Fig. 6. Effect of each phase's risks on project uncertainty

By using (4) and (15), we obtain the curves of duration uncertainty index (Figure 7). The value of $\Delta t$ in (7) is set to 0.1 week. Similarly, Figure 8 represents cost uncertainty index that are obtained from (16) and (18). Here, we used 50 dollars as the value of $\Delta \mathrm{c}$ for calculating cost entropy of activities. Table II represents the portion of each phase in uncertainty index of project for duration and cost uncertainties.

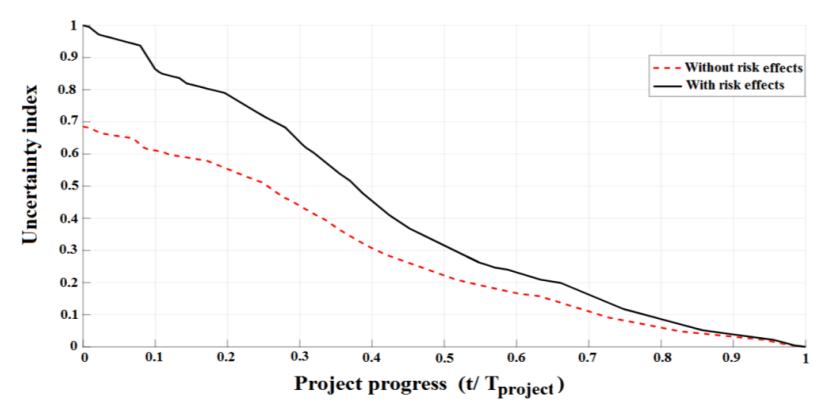

Fig. 7. Duration uncertainty index curve with and without risk effects

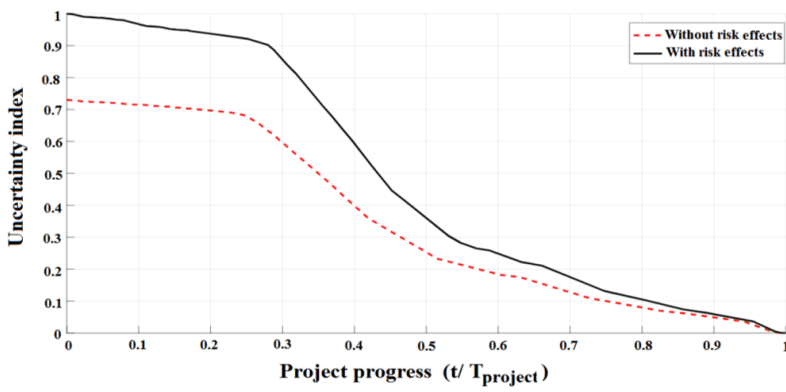

Fig. 8. Cost uncertainty index curve with and without risk effects

TABLE II. PORTION OF PROJECT PHASES IN PROJECT UNCERTAINTY

\begin{tabular}{|c|c|c|}
\hline Project phase & $\begin{array}{c}\text { Duration } \\
\text { uncertainty }\end{array}$ & $\begin{array}{c}\text { Cost } \\
\text { uncertainty }\end{array}$ \\
\hline Technical proposal & $4.3 \%$ & $1.3 \%$ \\
\hline Schematic design & $14.9 \%$ & $3.9 \%$ \\
\hline Technical project and detail design & $19.8 \%$ & $6.2 \%$ \\
\hline Preparing engine prototypes & $36.7 \%$ & $62.5 \%$ \\
\hline Ground and flight tests & $24.3 \%$ & $26.1 \%$ \\
\hline
\end{tabular}

The results are obtained with considering risk effects (black curves in Figures 7,8)

Finally, by results of uncertainty index for duration and cost of project (Figures 7 and 8) and using (19), overall project uncertainty index is obtained (Figure 9). Here, we assumed $\mathrm{K}=1$ in (19) which means that on-time completion of project and within determined budget have the same importance.

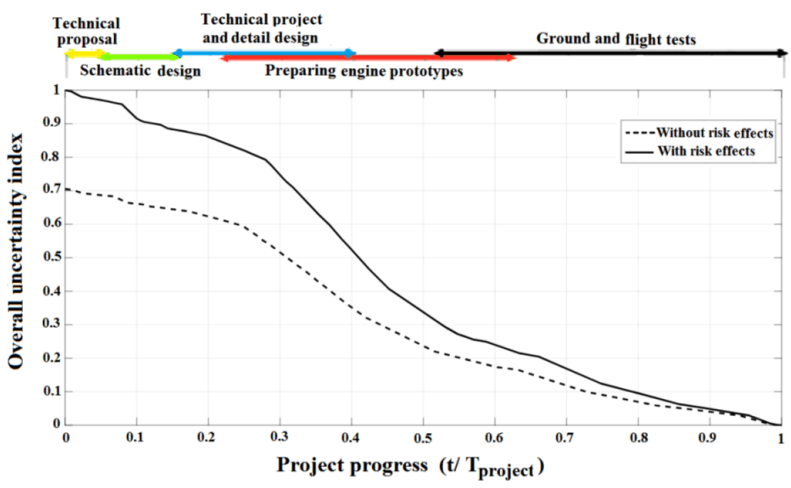

Fig. 9. Overall project uncertainty index curves (for $\mathrm{K}=1$ )

\section{DISCUSSION}

As shown in Figure 5 the relative uncertainty increase as the result of risk factors is higher for first phases (design activities) in comparison with last activities. This is mainly due to the nature of the design phase in these project types, which is associated with high uncertainty and the need for repeating or increasing the work amount. Moreover, this Figure shows us that activities $6,18,39,48$ and 57 are the most sensitive activities of each phase to risk factors. In performing each phase, special attention must be paid to risk management strategies for these activities. The influence of rework risk types on project uncertainty is higher than other risk types as they affect set of activities and not a single one. Given that out 
of 19 rework risks 7 reworks start from schematic design (second phase) and 9 reworks from ground and flight tests (fifth phase) it does not seem surprising that in Figure 6 these phases has higher effects on project uncertainty. For managing project risks, this risk type must be considered more seriously.

Analyzing Figures 7 and 8 and the corresponding values on Table II show that at first 3 phases, the project uncertainty due to activity durations is $3 \%, 11 \%, 13.6 \%$ more than uncertainty due to activity costs for the first, second and third phases respectively. However, this is because of the fact that for design activities the activity cost aspect is not as significant and prominent as activity durations. Figure 9 can be employed as an effective quantitative tool for investigating the impact of different risk management methods on project uncertainty level. The result of implementing risk management methods that attempt decreasing probability or impact of risks, can be represented by a curve between two curves of Figure 9 (without risk effects and with all possible risks). The relative area between two curves that is decreased by implementing risk management method can be considered as a quantitative measure for evaluating the effectiveness of that risk management method.

\section{CONCLUSION}

The results of this study lead to the evaluation of uncertainty in projects with a quantitative measure. This measure can be represented in different forms such as uncertainty of each activity and its increase due to risk effects, uncertainty of project as a function of time (project progress) and uncertainty with respect to duration, cost or other parameters. This information can be useful for project managers and other stakeholders for analyzing and selecting the effectiveness of different risk management and uncertainty controlling methods.

\section{REFERENCES}

[1] Project management Institute, A guide to the project management body of knowledge (PMBOK $®$ guide), 2013

[2] A. De Meyer, C. H. Loch, M. T. Pich, "Managing project uncertainty: from variation to chaos", MIT Sloan Management Review, Vol. 43, No. 2, pp. 60-67, 2002
[3] A. Asllani, L. Ettkin, "An entropy-based approach for measuring project uncertainty", Journal of Management Information and Decision Sciences, Vol. 10, No. 1, pp. 31-46, 2007

[4] S. D. Bushuyev, S. V. Sochnev, "Entropy measurement as a project control tool", International Journal of Project Management, Vol. 17, No. 6, pp. 343-350, 1999

[5] H. Song, D. Wu, M. Li, C. Cai, J. Li, "An entropy based approach for software risk assessment: A perspective of trustworthiness enhancement", 2nd International Conference on Software Engineering and Data Mining (SEDM), pp. 575-578, China, June 23-25, 2010

[6] C. C. Tseng, P. W. Ko, "Measuring schedule uncertainty for a stochastic resource-constrained project using scenario-based approach with utilityentropy decision model", Journal of Industrial and Production Engineering, Vol. 33, No. 8, pp. 558-567, 2016

[7] W. J. Cosgrove, "Entropy as a measure of uncertainty for PERT network completion time distributions and critical path probabilities", California Journal of Operations Management, Vol. 8, No. 2, pp. 20-26, 2010

[8] Е. А. Кузьмин, “Организационно-Экономические Системы В Условиях Неопределенности И Определенности: Оценка Значений Энтропии И Негэнтропии”, Управленец, Vol. 11-12, No. 40, pp. 4454, 2012 (Y. A. Kuzmin, "Organisational and economic systems under uncertainty and certainty: entropy and negentropy evaluation", Upravlenets, Vol. 11-12, No. 40, pp. 44-54, 2012)

[9] В. Н. Красников, "Неопределённость, энтропия и проектные риски", Радіоелектронні і комп'ютерні системи, Vol. 4, No. 31, pp. 87-91, 2008 (V. N. Krasnikov, "Uncertainty, entropy and project risks", Radioelectronic and Computer Systems, Vol. 4, No. 31, pp. 87-91, 2008 )

[10] В. Н. Красников, Е.В. Соколова, И.Б. Туркин, “Управления рисками сложных проектов авиационно-космической отрасли", Авиационно-космическая техника и технология, Vol. 3, No. 90, pp. 113-116, 2012 (V. N. Krasnikov, E. V. Sokolova, I. B. Turkin, "Risk management of complex projects aerospace industry", Aerospace Engineering and Technology, Vol. 3, No. 90, pp. 113-116, 2012)

[11] R. Tavakkoli-Moghaddam, S. Mousavi, H. Hashemi, "A fuzzy comprehensive approach for risk identification and prioritization simultaneously in EPC projects", in: Risk Management in Environment, Production and Economy, InTech, 2011

[12] V. Gogunsky, Y. S. Chernega, E. Rudenko, "Markov model of risk in the life safety projects", Odes'kyi Politechnichnyi Universytet. Pratsi, Vol. 41, No. 2, pp. 271-276, 2013

[13] C. E. Shannon, "A Mathematical Theory of Communication", Bell System Technical Journal, Vol. 27, pp. 379-423, 1948

[14] A. Chenarani, E. A. Drughinin, D. N. Kritskiy, "Simulating the impact of activity uncertainties and risk combinations in R\&D projects", Journal of Engineering Science and Technology Review, Vol. 10, No. 4, pp. 1-9, 2017 , 